\title{
Fatty Acid Langmuir Films on Liquid Mercury: X-ray and Surface Tension Studies
}

\author{
H. Kraack, ${ }^{\dagger}$ B. M. Ocko, ${ }^{\ddagger}$ P. S. Pershan, ${ }^{\S}$ E. Sloutskin, ${ }^{\dagger}$ L. Tamam, ${ }^{\dagger}$ and \\ M. Deutsch*, + \\ Department of Physics, Bar-Ilan University, Ramat-Gan 52900, Israel, Department of Physics, \\ Brookhaven National Laboratory, Upton, New York 11973, and Department of Physics, \\ Harvard University, Cambridge, Massachusetts 02138
}

Received J anuary 2, 2004. In Final Form: April 2, 2004

\begin{abstract}
The structure and phase behavior of liquid-mercury-supported molecular films of fatty acids $\left(\mathrm{CH}_{3}\left(\mathrm{CH}_{2}\right)_{n-2} \mathrm{COOH}\right.$, denoted $\left.\mathrm{CnOOH}\right)$ werestudied for molecular lengths $7 \leq \mathrm{n} \leq 24$, by surfacetensi ometry and X-ray methods. Two qualitatively different film structures were found, depending on coverage. For high coverage, the film consists of a monolayer of roughly surface-normal molecules, showing a pressuredependent sequenceof structures similar, though not identical, tothat of thecorresponding water-supported L angmuir films. At low coverage, phases consisting of surface-parallel molecules are found, not observed on the aqueous subphases employed to date. In this range, a two-dimensional (2D) gas fol lowed by a single and, for $14 \leq n \leq 24$, also by a double layer of surface-parallel molecules is found as coverage is increased. Depending on chain length, the flat-lying phases have a crystalline2D-ordered, a smectic-like 1D-ordered, or a disordered in-plane structure consisting of molecular dimers. The structure and thermodynamics of the films are discussed.
\end{abstract}

\section{Introduction}

Langmuir monolayers of fatty acids on water served as the model of choicefor studies of $L$ angmuir fil ms sincethe first quantitative measurements of Agnes Pockels on stearic acid over a century ago. ${ }^{1} \mathrm{~N}$ aturally, they have been also among the first three Langmuir monolayers studies byX-ray methods, published contemporaneously in $1987 .{ }^{2}$ Langmuir films were, and are, extensively studied in physics as a model for two-dimensional matter ${ }^{3}$ in biology as a model for the cell membrane, and in chemistry as templates for oriented growth of crystals from solutions, ${ }^{4}$ etc. They are being currently studied also as means for nanoengineering in general and nanopatterning of surfaces in particular, for studies of self-assembly of supramolecular structures, and as a promising route for constructing few-molecule el ectronic devices. ${ }^{3,5}$

The vast majority of all experimental studies of Langmuir films over the last century employed a variety of macroscopic methods. Surface tensiometry, the most prominent of these methods, provides a description of the surface thermodynamics through surface pressure $(\pi)$-molecular area (A) isotherms. ${ }^{6}$ With the advent of

\footnotetext{
* Towhom correspondencemay beaddressed. E-mail: deutsch@ mail.biu.ac.il.

${ }^{\dagger}$ Bar-Ilan University.

‡ Brookhaven National Laboratory.

$\S$ Harvard University.

(1) Pockels, A. Nature 1891, 43, 437.

(2) Grayer Wolf, S.; Leiserowitz, L.; Lahav, M.; Deutsch, M.; Kjaer, K.; Als-Nielsen, J. Nature 1987, 328, 63. Kjaer, K.; Als-Nielsen, J .; Helm, C. A.; Laxhuber, L. A.; Möhwald, H. Phys. Rev. Lett. 1987, 58, 2224. Dutta, P.; Peng, J. B.; Lin, B.; Ketterson, J. B.; Prakash, M.; Georgopoulos, P.: Ehrlich, S. Phys. Rev. Lett. 1987, 58, 2228.

(3) Kaganer, V. M.; Möhwald, H.; Dutta, P. Rev. Mod. Phys. 1999, 71,779 .

(4) Rapaport, H.: Kuzmenko, I: Berfeld, M. Kjaer, K : Als-Nielsen, J .; Popovitz-Biro, R.; Weissbuch, I.; Lahav, M.; Leiserowitz, L.J . Phys. Chem. B 2000, 104, 1399.

(5) Molecular Electronics; J ortner, J ., Ratner, M., Eds.; Blackwell: Oxford, 1997. Samori, P.; Rabe, J. P. J . Phys.: Condens. Matter 2002 14, 9955.

(6) Gaines, G. L. Insoluble Monolayers at Liquid-Gas Interfaces; Wiley-Interscience: New York, 1966.
}

synchrotron-based liquid surface X-ray scattering techniques, ${ }^{7-10}$ it became possible to study the structure of these films in situ with ångström scale resolution. Over the last two decades, these X-ray methods have been employed in studies of many Langmuir films. ${ }^{3,8,10-12}$ The structure of fatty acid Langmuir films on aqueous subphases, in particular, was investigated in detail as a function of chain length and temperature. ${ }^{3}$ Peterson and co-workers ${ }^{13}$ were able to show that as far as the phase diagram is concerned, a decrease in temperature is equivalent to an increase in chain length in these films. Oncethis effect is accounted for quantitatively, the phase diagrams of fatty acids of all chain lengths were found to mergeinto one "universal" phase diagram. Therich phase diagram which emerged from these experimental studies supported a detailed theoretical description and interpretation within a Landau-type mean-field theory by Kaganer and Luginov. ${ }^{14}$ Despite this great progress, new phases, like a phase with an intermediate tilt between nearest- and next-nearest neighbor directions, ${ }^{15}$ and novel effects, likea shift in thephaseboundaries upon thetuning

(7) Als-Nielsen, J :; Christensen, F .; Pershan, P. S. Phys. Rev. Lett. 1984, 48, 1107; Pershan, P. S.; Als-Nielsen, J . Phys. Rev. Lett. 1984, 52 759.

(8) Als-Nielsen, J .; J acquemain, D.; Kjaer, K.; Leveiller, F.; Lahav, M.; Leizerrowitz, L. Phys. Rep. 1994, 246, 252.

(9) Als-Nielsen, J .; Christensen, F .; Pershan, P. S. Phys. Rev. Lett. 1982, 48, 1107

(10) Penfold, J . Rep. Prog. Phys. 2001, 7, 777.

(11) Kuzmenko, I ; Rapaport, H : Kjaer, K ;Als-Nielsen, J :Weissbuch I.; Lahav, M.; Leiserowitz, L. Chem. Rev. 2001 101, 1659.

(12) Fukuto, M.; Penanen, K.; Heilmann, R. K.; Pershan, P. S. Vaknin, D. J . Chem. Phys. 1997, 107, 5531. Fukuto, M.; Heilmann, R. K.; Pershan, P. S.; Yu, S. M.; Griffiths, J. A.; Tirrell, D. A. J . Chem Phys. 1999, 111, 9761. Fukuto, M.; Heilmann, R. K.; Pershan, P. S.; Yu, S. M.; Soto, C. M.; Tirrell, D. A. Phys. Rev. E 2002, 66, 010601. Vaknin, D. Physica B 1996, 221, 152. Mouri, E.; Nakanishi, T.; Nakashima, N.; Matsuoka, H. Langmuir 2002, 18, 10042

(13) Bibo, A. M.; Peterson, I. R. Adv. Mater. 1992, 2, 309. Peterson I. R.; Brzezinski, V.; Kenn, R. M.; Steitz, R. Langmuir 1992, 8, 2995

(14) Kaganer, V. M.; Loginov, E. B. Phys. Rev. Lett 1993, 71, 2599; Phys. Rev. E 1995, 51, 2237.

(15) Durbin, M. K.; Malik, A.; Richter, A. G.; Ghaskadvi, R.; Gog, T.; Dutta, P. J . Chem Phys. 1997, 106, 8216. 
of the interactions between the headgroups, ${ }^{16}$ are still being discovered. F urther details of the plethora of results obtained for fatty acids on aqueous sol utions can befound in several excellent reviews published over the past decade. $3,4,8,11$

Until recently, all X-ray studies of L angmuir films were carried out on aqueous subphases. On such subphases, the strong hydrophobic repulsion of the fatty acid's tail from the surfaceinvariably orients the molecules roughly along, or slightly tilted from, the surface normal. To the best of our knowledge, the only nonaqueous subphase employed in X-ray studies of a Langmuir film is formamide, 11,17,18 which is also polar and induces the same surface-normal molecular orientation. To investigate the rol eof themolecules' interaction with the subphasein the determination of the Langmuir film's structure, we have undertaken to study the structure of Langmuir films of organic molecules on mercury. Mercury does not induce a hydrophobic repulsion of the chains from the surface but rather provides an attractive interaction with the chains. It also does not providea hydration shell for ionic headgroups. It has several technical advantages over water. The high surface energy of mercury, $\sim 500 \mathrm{~mJ} / \mathrm{m}^{2}$, as compared to that of water, $72 \mathrm{~mJ} / \mathrm{m}^{2}$, enhances the spreadability of films and allows spreading of molecules that are not readily, or not at all, spreadable on water. The practically zero solubiliti es of all organic compounds, and most inorganic ones, in mercury all ows investigation of Langmuir films of compounds which cannot be studied on water due to their high water solubility. As shown below, the higher surface tension of mercury also all ows extension of theX-ray reflectivity measurements to 4-fold larger scattering vectors, yielding a commensurately higher resolution as compared to those achievable on water. The important differences in both tail and headgroup interactions with the subphase enables investigations over a considerably broader scope of properties of Langmuir films than those available in Langmuir films on aqueous subphases only. This should provide for a deeper insight into the role of the subphase in forming the structure and phase diagram of Langmuir films.

Knowing the surface structure of bare mercury is a prerequisitefor any study of mercury-supported Langmuir films. We have determined this structure with subångström resolution a few years ago, ${ }^{19}$ using surface $X$-ray techniques. This was followed by a study of dense selfassembled al kanethiol monolayers ${ }^{20}$ and multilayers ${ }^{21}$ on thesurface of mercury. Very recently we presented results for stearic acid on mercury 22 and a systematic study of the chain length variation of thestructureand phasediagram of $L$ angmuir films of al kanes on mercury. ${ }^{23}$ For both fatty acids and alkanes, the attractive interaction of the alkyl tail with the subphase induces, at low coverages, new phases comprising surface-parallel molecules, not ob-

(16) J ohann, R.; Vollhardt, D.; Möhwald, H. Langmuir 2001, 17, 4569.

(17) Saint J almes, A.; Graner, F .; Gallet, F.; Nassoy, P.; Goldmann,

M. Chem. Phys. Lett. 1995, 240, 234.

(18) Weinbach, S. P. et al. J. Phys. Chem. 1993, 97, 5200.

(19) Magnussen, O. M.; Ocko, B. M.; Regan, M. J .; Penanen, K.; Pershan, P. S.; Deutsch, M. Phys. Rev. Lett. 1995, 74, 4444. DiMasi, E.; Tostmann, H.; Ocko, B. M.; Pershan, P. S.; Deutsch, M. Phys. Rev. B 1998, 58, 13419

(20) Magnussen, O. M.; Ocko, B. M.; Deutsch, M.; Regan, M.J .; Pershan, P. S.; Abernathy, D.; Grübel, G.; Legrand, J . F . Nature 1996, 384, 250.

(21) Deutsch, M.; Magnussen, O. M.; Ocko, B. M.; Regan, M. J .; Pershan, P. S. Thin Films: Self-Assembled Monolayers of Thiols; UIman, A., Eds.; Academic: San Diego, CA, 1998.

(22) Kraack, H.; Ocko, B. M.; Pershan, P. S.; Sloutskin, E.; Deutsch, M. Science 2002, 298, 1404.

(23) Kraack, H.; Ocko, B. M.; Pershan, P. S.; Sloutskin, E.; Deutsch, M. J . Chem. Phys. 2003 119, 10339.

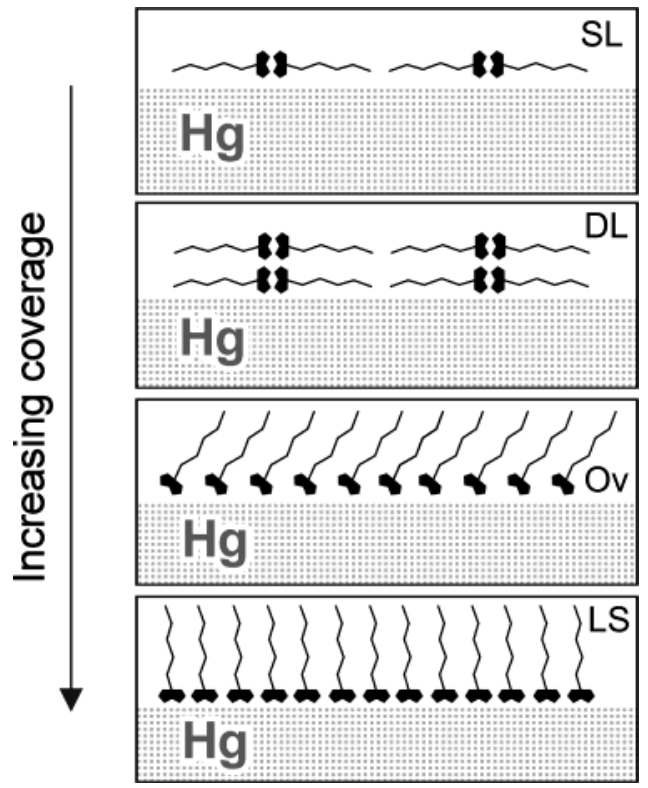

Figure 1. Schematic real space model of a Langmuir film of stearic acid on mercury. With increasing coverage stearic acid shows successively a single (SL) and a double (DL) layer of lying-down molecules, a tilted phase of standing-up molecules (Ov) and an untilted phase of standing-up molecules (LS).

served on water. For alkanes only surface-parallel phases (of up to three layers) are found for all chain lengths. In contrast, stearic acid on mercury exhibits phases with surface parallel molecules at low coverages and phases with surface-normal molecules at high coverages.22 The surface-normal phases have structures very similar to those of stearic acid on water. A schematic view of the real-space structure of the various surface-normal and surface-parallel phases found for $\mathrm{C} 180 \mathrm{OH}$ for different coverages is shown in Figure 1. Two surface-parallel phases, a single layer (SL) and a double layer (DL), are shown as well as two surface normal phases, one tilted (Ov) and one untilted (LS).

We present here a systematic study of the chain length dependence of the structure and phase diagram of fatty acids on mercury for a range of chain lengths and surface coverages, as well as first results on their temperature dependence.

Finally, self-assembled layers (SAMs) of organics on sol id substrates, mostly alkanethiols on gold, have been investigated extensively by X-ray, and other, methods, ${ }^{24-27}$ and surface-parallel phases werefound at certain coverage ranges. These SAMs should be, however, clearly distinguished from Langmuir films on a liquid substrate. While on a solid substrate the SAMs structure is largely determined by its epitaxy to the structure of the underlaying solid, on a liquid mercury subphase the film's molecules are not confined to lattice sites. Thus, varying the coverage is considerably simpler, and more accurate, on a liquid surface than on a solid one. More importantly, in themost extensively studied SAM s by far, alkanethiols on gold, the crystalline structure of the gold surface was found to determine the SAMs structure by epitaxy, both in the surface-normal ${ }^{26}$ and the surface-parallel ${ }^{27}$ phases. Since no static corrugation potential exists for a liquid surface like mercury, such epitaxy of the organic mono-

(24) Schreiber, F. Prog. Surf. Sci. 2000, 65, 151

(25) Poirer, G. Langmuir 1999, 15, 1167.

(26) Strong, L.; Whitesides, G. Langmuir 1988, 4, 546. Chidsey, C. E. D.; Loiacono, D. N. Langmuir 1990, 6, 682.

(27) Camillone, N.; et al. J . Chem. Phys. 1994, 101, 11031. 
layer to the structure of the subphase does not occur, resulting in less constraints for theemergence of different types of lateral order in the film.

\section{Experiment}

Theexperimental methods are discussed in detail in a previous publication. ${ }^{23}$ Thus, only a summary is given here.

A. The Langmuir Trough. A specially designed Langmuir trough, suitablefor simultaneous film balanceand X-ray studies, was used. It consisted of a $175 \times 65 \times 3.5 \mathrm{~mm}^{3} \mathrm{KelF}$ trough, enclosed in a hermetically sealed aluminum box. The box was filled with either helium (in X-ray measurements) or nitrogen (for surface tension measurements) to minimize mercury oxidation and air scatter during experiments. The temperature of the mercury is controllable to $\pm 0.2{ }^{\circ} \mathrm{C}$ by a water circulator.

The surface tension was measured using the Wilhelmy plate method, employing an $\mathrm{Hg}$-amalgamated platinum plate and a homemade balance based on an linear variable differential transformer (LVDT).

B. Materials. Tripledistilled, 99.999\% mercury was purchased from Merck. Fatty acids were purchased from Fluka or Aldrich and were at least $99 \%$ pure. All materials were used as received without further purification. Standard solutions were prepared with molarities in the range of $(3-8) \times 10^{-4}$ using HPLC grade, 99.9\% pure chloroform.

C. Measurement Methods. 1. Surface Pressure-Molecular Area Isotherms. The surface pressure, $\pi=\sigma_{0}-\sigma$, the difference between the surface tensi on of the bare $\left(\sigma_{0}\right)$ and the film-covered $(\sigma)$ mercury varies with the surface coverage, $\mathrm{A}$, the area per molecule. ${ }^{6}$ F eatures in the $\pi$ vs A isotherm curve (e.g., kinks, plateaus, etc.) reveal the occurrence of structural changes in the film as the coverage $A$ is varied.

Sincea well-sealing barrier is notoriously difficult to construct for mercury, ${ }^{28}$ the coverage was increased not by barrier compression but rather by a stepwise addition of standard solution, employing calibrated mi cropipet. In each step material was added only after a full pressure equilibration of the previous step was reached..$^{23}$

2.X-ray Measurements. Thestructure of thedeposited films was studied at several coverages using surface-specific X-ray techniques. These were done using the Harvard/BNL liquid surface spectrometer at beamline X22B, NSLS, Brookhaven National Laboratory, U.S.A., at wavelengths of $\lambda=1.55-1.58$ $\AA$. Thetrough was mounted on an active vibration isolation unit, attached to the spectrometer. This arrangement effectively eliminates pickup of vibrations from theenvironment, $19,20,23$ which plagued early X-ray surface studies of mercury. ${ }^{29}$

TheX-ray methods used here have been discussed in detail. 3,9,30 The surface-normal structure was studied by X-ray reflectivity $(X R)$ measurements, $R\left(q_{z}\right)$, done by varying the surface-normal momentum transfer $q_{z}=(2 \pi / \lambda)(\sin \alpha+\sin \beta)$ where $\alpha$ is the grazing angle of inci dence of theX-ray beam and $\beta$ is thegrazing angle of detection. Grazing incidence diffraction (GID) was measured by varying the surface-parallel momentum transfer $\mathrm{q}_{\|}=(2 \pi / \lambda)\left(\cos ^{2} \alpha+\cos ^{2} \beta-2 \cos \alpha \cos \beta \cos 2 \theta\right)^{1 / 2} \approx(4 \pi / \lambda)$ $\sin (2 \theta / 2)$ by scanning the detector out of the reflection plane by an angle $2 \theta$ at incidence angles $\alpha<\alpha_{c}$, where $\alpha_{c}$ is the critical angle for total external reflection. The GID measurements provided information on the surface-parallel structure. Braggrod (BR) measurements (the surface-normal distribution of the diffracted intensity at the $2 \theta$ positions of the GID diffraction peaks) yielded information on the molecular tilt magnitude and direction. To minimize beam damage, $\mathrm{X}$-ray exposuretimes were minimized by using an automatic shutter, which was opened only for counting, and kept closed during spectrometer move ments, wait times, etc.

3. X-ray Reflectivity Modeling. Thedetails of the modeling are given in ref 23 . The box model that was used in the previous

(28) Smith, T. Adv. Colloid Interface Sci. 1972, 3, 161.

(29) Barton, S. W.; Thomas, B. N.; Novak, F.; Weber, P. M.; Harris, 1.; Dolmer, P.; Bloch, J. M.; Rice, S. A. Nature 1986, 321, 685. Lu, B. C.; Rice, S. A. J . Chem. Phys. 1978, 68, 5558. Bosio, L.; Oumezine, M. J .Chem. Phys. 1984, 80, 959. Bosio, L.; Cortes, R.; Folcher, G.; Froment, M. J . Electrochem. Soc. 1992, 139, 2110.

(30) Pershan, P. S.; Als-Nielsen, J . Phys. Rev. Lett. 1984, 52, 759. studies of alkanes on mercury was also used here. We experimented with a variety of different combinations of fixed and varying parameters before settling on the following specifics. The layered mercury surface ${ }^{19}$ was represented by six boxes, each having a fixed width of $1.3 \AA$ (half the liquid mercury layer spacing), and a fixed interface roughness of $0.7 \AA$. The electron density of each box was varied in the fit, except for the topmost one, which was kept fixed at $5.5 \mathrm{e} / \AA^{3}$. I n view of the fact that for this study the maximum value of $\mathrm{q}_{\mathrm{z}}$ was of the order of 1.5-1.7 $\AA^{-1}$, which is significantly less than the maximal $2.5 \AA^{-1}$ used in our detailed study of the bare mercury surface, ${ }^{19}$ the model employed here is slightly less general. Nevertheless, our model yiel ds a good fit to the reflectivity curves of the bare, and the fatty acid covered, mercury surface measured in this $\mathrm{q}_{\mathrm{z}}$ range, and the fit-obtained mercury layering profile is very close to those of the earlier studies. ${ }^{19,23,31}$

The fatty acid layers were also represented by boxes. For the lying-down phases, for each layer a single box with an electron density of $\rho=0.30$ electrons $/ \AA^{3}$ was found to fit the measured $\mathrm{R}\left(\mathrm{q}_{\mathrm{z}}\right)$ well. For the standing-up phases two boxes were used, representing the alkyl chain (with the same $\rho=0.30$ el ectrons/ $\AA^{3}$ ) and the carboxyl headgroup (with a fixed el ectron density of 0.46 electrons $/ \AA^{3}$ and a width of $2.5 \AA$ ). The thicknesses of the boxes of the lying down phase were first fitted freely and then fixed at the average values of $4.8 \AA$ for a single layer and $9.6 \AA$ for a double layer.

TheParrat matrix method ${ }^{32}$ was employed to fit the measured $R\left(q_{z}\right)$ data. When we had two phases in coexistence with each other, e.g., a phase of standing-up molecules in coexistence with a phase of lying-down molecules, we fitted the measured XR by a sum of the model intensities reflected from each phase. As demonstrated by theresults discussed below, and by our previous studies using the same method, ${ }^{23,31}$ the model and strategy employed here yield good fits to the measurements. Consistent trends areobtained in thefitted parameter values with coverage. At the same time, the number of fit parameters is kept down to a manageable number and the interparameter correlations to a minimum. This lends confidence in the results and conclusions discussed below.

Further details on the trough, the measurement procedures, and data analysis methods are given in ref 23.

\section{Results: Surface Pressure-Area Isotherms}

Themeasured surface pressure-area isotherms for fatty acids of several chain lengths, $7 \leq n \leq 24$, are shown in Figure 2. The various parameter values derived from the isotherms are listed in Table 1 . The isotherms were all measured at a temperature $\mathrm{T}=23^{\circ} \mathrm{C}$. A smooth sol id line connects the measured points (open circles). The dashed lines at large molecular areas are fits by the Volmer equation, $\pi\left(A-A_{1}\right)=k_{B} T$, the ideal gas law in two dimensions for molecules of a nonzero area $A_{1}$. Although the fit is not perfect, the agreement of all isotherms with the Volmer equation is reasonable, in the sense that the exclusion areas $A_{1}$ obtained from thefits (shown in Figure 3 and listed in Table 1) are close, within their admittedly rather largeexperimental uncertainties, tothecalculated area occupied by a flat lying molecule, $A_{1}$ calc $=4.8(1.265 \mathrm{n}$ $+1.86) \AA^{2} /$ mol ecule, obtained from thewidth, $w \approx 4.8 \AA, 22$ and length, $\mathrm{I} \approx 1.265 \mathrm{n}+1.86 \AA^{33}$ of a $\mathrm{CnOOH}$ molecule. A linear fit, shown in a solid line in Figure 3 , to the measured $A_{1}$ values yields $A_{1}=[(6.5 \pm 0.4) n+(0.1 \pm 6)]$ $\AA^{2} /$ molecule, again, very close to the $A_{1}$ calc values, shown

(31) Kraack, H.; Ocko, B. M.; Pershan, P. S.; Deutsch, M. Science 2002, 298, 1404

(32) Lekner, J . Theory of Reflection; Martinus Nijhoff: Dordrecht, 1987. Abeles, F. Ann. Phys. (Paris) 1950, 5, 596. Ocko, B. M.; Wu, X Z.; Sirota, E. B.; Sinha, S. K.; Gang, O.; Deutsch, M. Phys. Rev. E 1997, 55,3164

(33) Kjaer, K.; et al. J . Phys. Chem. 1989, 93, 3200. Petrov, J ; et al. J . Phys. Chem B 1999, 103, 3417. H owever, theheadgroup sizes derived in thesestudies correspond to hydrated carboxylic headgroups and were reduced here, somewhat arbitrarily, by the radius of a water molecule, $\sim 1.4 \AA$. 


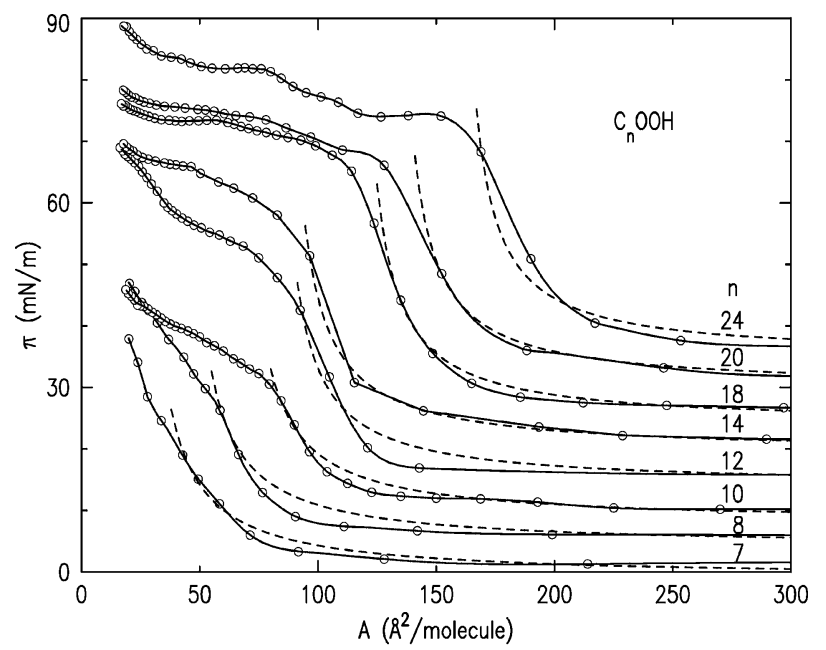

Figure 2. Surface pressure $(\pi)$-area per molecule $(A)$ isotherms for fatty acids of different chain lengths $7 \leq n \leq 24$ (solid lines + points), shifted for clarity by $\pi=5 \mathrm{mN} / \mathrm{m}$ each. The fit to the Volmer equation is shown in dashed lines.

Table 1. Exclusion Areas for Fatty Acids of Chain Lengths $n$ As Obtained from Fits of the Measured Isotherms by the Volmer Equation Assuming Monomers, $A_{1}$, and Dimers, $A_{d / 2}$, and by the van der Waals Equation, $A_{v d w^{2}}$

\begin{tabular}{|c|c|c|c|c|c|c|c|c|}
\hline \multirow[b]{2}{*}{$\mathrm{n}$} & \multicolumn{5}{|c|}{$\AA_{2} /$ molecule } & \multicolumn{3}{|c|}{$\mathrm{mN} / \mathrm{m}$} \\
\hline & $A_{1}$ & $A_{v d W}$ & $A_{d / 2}$ & $\mathrm{~A}_{1}$ calc & $A_{2}$ & $\pi_{1}$ & $\pi_{2}$ & $\pi_{\mathrm{c}}$ \\
\hline 7 & $23(5)$ & 27 & 32 & 51.4 & & 11 & & 38 \\
\hline 8 & $41(6)$ & 46 & 49 & 57.5 & & 20 & & 42 \\
\hline 10 & $68(7)$ & 69 & 74 & 69.6 & & 26 & & 37 \\
\hline 12 & $80(7)$ & 80 & 86 & 81.8 & & 33 & & 52 \\
\hline 14 & $83(7)$ & 85 & 91 & 93.9 & $45(5)$ & 39 & 46 & 49 \\
\hline 18 & $115(8)$ & 118 & 124 & 118.2 & $62(5)$ & 41 & 47 & 50 \\
\hline 20 & $130(10)$ & 132 & 141 & 130.4 & $71(6)$ & 39 & 45 & 49 \\
\hline 24 & 157(10) & 157 & 162 & 154.7 & $76(7)$ & 38 & 46 & 53 \\
\hline
\end{tabular}

a Theexperimental uncertainty is given in parentheses. Thearea occupied by a flat-lying mol ecule as cal culated from its geometrical dimensions, $A_{1}$ calc, and the area at the beginning of the second plateau $A_{2}$ (as observed in theisotherm) areal solisted. The surface pressures, $\pi_{1}$ and $\pi_{2}$ at $A_{1}$ and $A_{2}$, respectively, and the collapse pressure, $\pi_{c}$, are also given

as a dash line in Figure 3. A similar agreement of the Volmer equation with the measured isotherms, and of $A_{1}$ with $A_{1}$ calc, was also observed for alkanes on mercury ${ }^{34}$ and for $\mathrm{C} 180 \mathrm{OH}$ on mercury. ${ }^{22}$ There, as here, this agreement is interpreted as indicating that the Langmuir film in the low coverage regime consists of a "gas" of flatlying molecules. This conclusion is supported by the X-ray results to be described below. While it is possible, and even plausible, that in the low coverage region, $A \gg A_{1}$, the "gas" phase actually consists of at least two Adependent phases, quasi-2D gas and liquid, rather than a single "gas" phase, our surface pressure and X-ray measurements did not reveal any features that could be associated with transitions between such phases. F urther measurements, in particular high-resolution isotherm measurements, are required to elucidate the structure of the Langmuir film in this regime.

Fits to the two-dimensional van der Waals equation ${ }^{35}$ $\left(\pi+a / A^{2}\right)\left(A-A_{v d w}\right)=k_{B} T$, with theinteraction parameter $a$ and the exclusion area $A_{v d w}$, wereonly marginally better and resulted in practically the same exclusion area as for

(34) Kraack, H.; Deutsch, M.; Ocko, B. M.; Pershan, P. S. Nud. Instrum. Methods Phys. Res., Sect. B 2003, 200, 363.

(35) I sraelachvili, J . N. I ntermol ecular and Surface F orces, 2nd ed.; Academic: San Diego, CA, 1992.

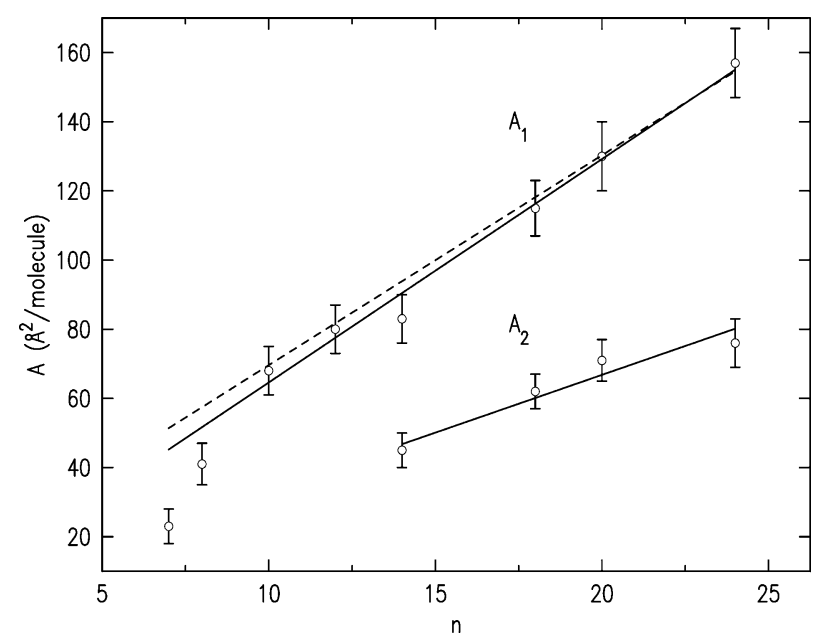

Figure 3. The Volmer-fitted exclusion area, $A_{1}$ (open circles), and starting point of the second plateau, $A_{2}$ (open circles), with linear fits (lines). The dash line shows thearea $A_{1}$ calc of a single molecule laying flat on the surface, as calculated from the molecular dimensions. The second plateau is observed for $n \geq$ 14 only. The decrease in $A_{1}$ bel ow thelines for $n \leq 8$ is discussed in the text.

thesimpler Volmer equation. Thus, both Volmer and van der Waals equations yield here an exclusion area $A_{1} \approx$ $A_{1}$ calc $r a t h e r$ than the $A_{1} \approx 2 A_{1}$ calc expected for a hard-disk liquid. ${ }^{35}$ This effect, found also for Langmuir films on water, was addressed in a number of theoretical 36,37 and experimental ${ }^{38}$ studies. The a values obtained from the fit exhibit a large scatter, as neither the van der Waals nor the Volmer equations of state follow closely enough the measured isotherms. The force constant of the longdistance molecular pair interaction should be related, in princi ple, to a. However, a reliable extraction of the force constant of any pair potential from the isotherms requires a better-fitting state equation, a more realistic effective pair potential (which will account for the chain-chain the chain-headgroup, and the headgroup-headrgroup interactions), and the derivation of an expression relating the force constant and the interaction parameter for the specific choices of potential and state equation.

As we show bel ow, the X-ray results reveal that the 2D gas at large A consists, at least for the longer molecules, of molecular dimers rather than singlemolecules. Wehave therefore carried out also fits assuming dimers rather than monomers as the basic structural units. These fits yielded slightly larger molecular exclusion areas, $A_{d / 2}=$ $[(6.6 \pm 0.3) n+(5 \pm 6)] \AA^{2} /$ mol ecule (see Table 1). These larger areas are more consistent with the lengths of the dimers derived from the X-ray measurements discussed below.

For coverages higher than the bend in the isotherm, i.e., $A<A_{1}$, three qualitatively different types of behavior are observed in theisotherms, depending on themolecular length $\mathrm{n}$. For $14 \leq \mathrm{n} \leq 24$, we find the same behavior which was observed in our study of stearic acid on mercury. ${ }^{22}$ As $A$ is reduced from $A_{1}$, we first obtain a

(36) I srael achvilli, J L angmuir 1994, 10, 3774. Seealsotheextensive recent work by Fainerman, V. B.; Volhardt, D. J . Phys. Chem. B 2003, 107,3098 , and in ref 38 , and several references therein. Notethat despite the graphic similarity with our isotherms, our $A_{1}$ does not correspond to $A_{c}$ in thesestudies, but rather to $A_{0}$ and $\omega$, respectively, i.e., the area occupied by a singlemol eculeat the monol ayer's most compressed state.

(37) Tonks, L. Private communication, cited in Langmuir, I. J . Am Chem. Soc. 1932, 54, 2798

(38) Vollhardt, D.; Fainerman, V. Colloids Surf., A 2001, 176, 117 Langmuir, I. J. Chem. Phys. 1933, 1, 756. Davies, J. T. Proc. R. Soc. London, Ser. A 1951, 208, 224. Phillips, J. N.; Rideal, E. Proc. R. Soc London, Ser. A 1955, 232, 149. 
plateau (in most cases with a small slope), then a step to a second, higher, plateau. When a molecular area of A $30 \AA^{2} /$ molecule is reached, a faster rise in the surface pressure is observed with decreasing $A$ until the film collapses at $A \leq 20 \AA^{2} /$ mol ecule, when we start observing small crystallites on the otherwiseclean mercury surface. The "two step" structure suggests the existence of both a single- and a double-layer phase of flat-lying molecules. As found in the stearic acid study ${ }^{22}$ the precollapse rise in the isotherm is dueto phases of standing up molecules, rendering the second, higher- $\pi$, plateau a coexistence region between lying down and standing up phases.

For $8 \leq \mathrm{n} \leq 12$ no second plateau and a rather sloping first plateau are observed. The bend at $A_{1}$ becomes less pronounced and practically disappears for $\mathrm{C7OOH}$. The surface pressure at the bend also decreases with decreasing $n$, yiel ding a shorter existence range for, and perhaps incomplete coverage of the surface by, a single layer of surface-parallel molecules. This phase seems to disappear completely for $\mathrm{C} 7 \mathrm{OOH}$ and shorter chain lengths. This suggested trend is supported also by the observed $n$ dependence of the fitted exclusion areas. For $10 \leq n \leq 24$ the measured $A_{1}$ values are well approximated by $A_{1}=$ $[(6.5 \pm 0.4) n+(0 \pm 6)] \AA^{2} /$ molecule, but for $n \leq 8$ the values fall bel ow the line, indicating that at $A_{1}$ a molecule occupies a surface area less than that required for a surface-parallel orientation. The exclusion area fitted for $\mathrm{C} 70 \mathrm{OH}, \mathrm{A}_{1} \simeq 23 \AA^{2} / \mathrm{molecule}$, is, in fact, cl ose to the $\sim 20$ $\AA^{2} /$ molecule occupied by a standing-up molecule. This suggests that the shorter-chain molecules tend to stand up already in the higher A parts of the isotherm and thus show a phase sequence closer to that of Langmuir films of fatty acids on water.

The areas at the beginning of the second plateau also grow linearly with $\mathrm{n}: \mathrm{A}_{2}=[(3.3 \pm 0.4) \mathrm{n}+(1 \pm 8)] \AA^{2} /$ molecule, very close to $A_{1} / 2$ and $A_{1}$ calc $/ 2$. This, and our earlier results for $\mathrm{C} 180 \mathrm{OH}$ on mercury, 22 suggests that the step at $A_{2}$ occurs on the completion of a double layer of flat-lying mol ecules. The isotherms show a cl ear trend of sharper transitions between the regimes, and flatter plateaus, with increasingmolecular length $\mathrm{n}$. This, in turn, indicates a better ordering of the molecules in the condensed layers for longer molecules. The structural suggestions made in this section, based on theisotherms, are further examined below in the light of the X-ray measurements described in the next section.

\section{Results: X-ray Measurements}

$X$-ray reflectivity and GID measurements were generally doneat the high $A$ end and the middl e of each plateau and close to the low A ends of the isotherms, where a strong rise in the surface pressure is observed. We now describe the X-ray results for two fatty acids, $\mathrm{C} 140 \mathrm{OH}$ and $\mathrm{C} 24 \mathrm{OOH}$, showing a different phase behavior and sequencefor the standing-up but similar behavior for the lying-down phases. For completion, a very short summary of our previously published results for $\mathrm{C} 180 \mathrm{OH}^{31}$ will also be given.

We discuss first the surface-normal structure at all coverages, and thein-planestructure of the morefamiliar monolayer phases of standing-up molecules, at $A \leq 30$ $\AA^{2} /$ molecule. The more novel in-plane structure of the single and double layers of flat-lying molecules observed for $A \geq 40 \AA^{2} /$ moleculeand, in particular, their variation with chain length and temperature will be discussed separately at the end of this section, to point out $\mathrm{n}$-dependent trends in these novel phases.

A. C1400H. 1. Surface Normal Structure. Figure 4a shows a set of reflectivities measured (points) at room
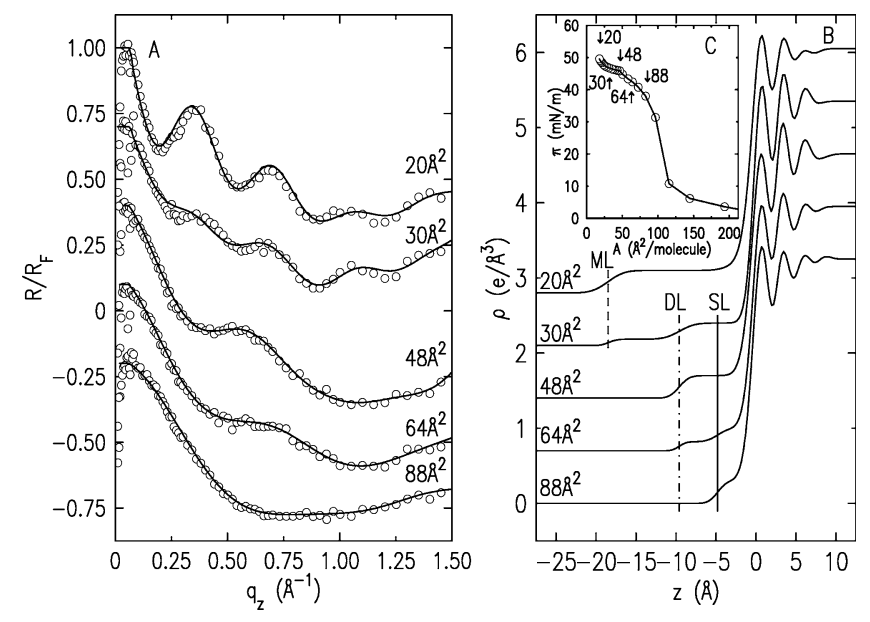

Figure4. (a) Measured, Fresnel-normalized X-ray reflectivities (points) for $\mathrm{C} 14 \mathrm{OOH}$ on mercury and their model fits (lines) for the listed area per molecule, taken at RT. (b) The electron density profiles derived from the fit. The curves marked SL and $\mathrm{DL}$ denote the thicknesses of the single and double layer of lying-down molecules and ML the thickness of a monolayer of standing-up molecules. (c) Theisotherm, with arrows marking the positions where X-ray data were measured. The XR in (a) show from bottom to top the successive growth of two layers of flat-Iying molecules, a coexistencebetween a standing-up phase and a two-layer lying-down phase, and a phase consisting of standing-up molecules only. The curves in both parts of the figure are shifted for clarity.

Table 2. Nominal Coverage (A) According to the Isotherms, Layer Thickness (d), Phase, Fractional Coverage of the Topmost Layer in \% (TOp), and the Roughness of the Fatty Acid-Air $\left(\sigma_{\mathrm{Fat}}\right)$ and the Mercury-Fatty Acid $\left(\sigma_{\mathrm{Hg}}\right)$ Interfaces, As Obtained from Fits to the XR Curves in Figure 4 for a C140OH Layer at $\mathbf{T}=25^{\circ} \mathrm{C}$

\begin{tabular}{crlccc}
\hline $\mathrm{A}, \AA^{2}$ & $\mathrm{~d}, \AA$ & phase & top, \% & $\sigma_{\text {Fat }}, \AA$ & $\sigma_{\mathrm{Hg}}, \AA$ \\
\hline 88 & 4.8 & $\mathrm{SL}$ & 100 & 0.9 & 1.1 \\
64 & 9.6 & $\mathrm{DL}$ & 40 & 1.2 & 1.3 \\
48 & 9.6 & $\mathrm{DL}$ & 100 & 1.0 & 1.2 \\
30 & 18.5 & $\mathrm{ML}$ & 30 & 1.2 & 1.0 \\
20 & 18.6 & $\mathrm{ML}$ & 100 & 1.5 & 1.2
\end{tabular}

temperature (RT) for $\mathrm{C} 1400 \mathrm{H}$ at the areas per molecule listed and shown by arrows in Figure 4c. The curves are normal ized totheF resnel reflectivity, $R_{F}\left(q_{z}\right)$, of an ideally flat and smooth mercury surface. Thebox model employed yields good fits (lines). The corresponding el ectron density profiles are shown in Figure $4 \mathrm{~b}$, with the mercury/alkane interface at $z=0$, and the Langmuir film at negative $z$ values. The parameter values obtained from the fit are summarized in Table 2. They al low a clear identification of the various phases, and the corresponding features in the isotherm shown in Figures 2 and 4c. All roughness values of the mercury-fatty acid and the fatty acid-air interfaces were in the range $0.9-1.5 \AA$, close to those of a puremercury surface. ${ }^{19} \mathrm{As}$ listed in thetable, and shown by arrows in Figure 4c, with increasing coverage, SL and $\mathrm{DL}$ phases of lying-down mol ecules and a monolayer (ML) phase of standing-up molecules are found, with a coexistence region between the standing-up and lying-down molecules. The standing-up ML phase is found to be 18.6 $\AA$ thick. This is slightly less than, but closetotheextended length of a $\mathrm{C} 140 \mathrm{OH}$ molecule, $19.6 \AA$, indicating a phase of almost untilted standing-up mol ecules.

2.SurfaceParallel Structure. Tostudy themolecular tilt and thein-planestructure of $\mathrm{C} 14 \mathrm{OOH}$, wehavecarried out GID and BR measurements. These measurements were done at several temperatures to elucidate the temperature dependence of the structure. The GID scans 

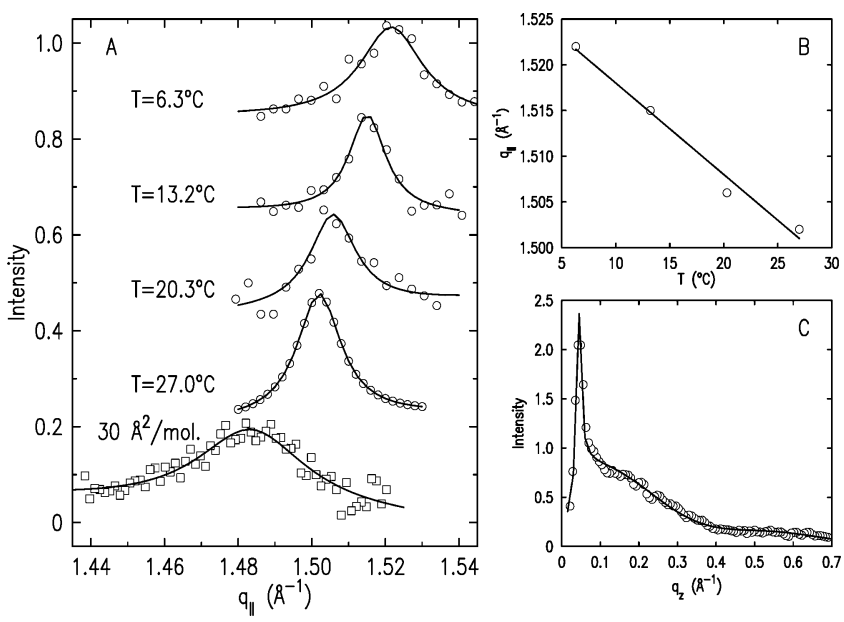

Figure 5. GID scans for the standing-up phase of $\mathrm{C} 140 \mathrm{OH}$. (a) GID scans at $A=20 \AA^{2} / \mathrm{mol}$ ecul efor thelisted temperatures and for $\mathrm{A}=30 \AA^{2} / \mathrm{molecule}$ for $\mathrm{T}=27.0^{\circ} \mathrm{C}$. The single peak found indicates an hexagonal in-plane structure. (b) The temperature dependence of the GID peak's position. (c) BR for $\mathrm{A}=20 \AA^{2} / \mathrm{molecule}$ at $\mathrm{T}=27.0{ }^{\circ} \mathrm{C}$ showing a monolayer of untilted molecules. There were no measurable differences in the BR for the different temperatures.

are shown in Figure 5 for the same coverage of $20 \AA^{2} /$ molecule, except for the bottom curve that was taken at $\mathrm{T}=27.0^{\circ} \mathrm{C}$ and a coverage of $30 \AA^{2} /$ molecule.

For all measured temperatures $T$ and coverages $\mathrm{A} \leq 30$ $\AA^{2} /$ mol ecule, i.e., for thestanding-up phases, a singleGI D peak was observed, indicating an undistorted hexagonal unit cell. Whilethewidth of the GID peaks does not change significantly with temperature, the peak positions clearly change linearly with $\mathrm{T}$, as shown in Figure $5 \mathrm{~b}$. Assuming the peak shift to result only from thermal expansion, the expansion coefficient obtained from a linear fit to the peak positions at Figure $5 \mathrm{~b}$ is $(\mathrm{dd} / \mathrm{dT}) / \mathrm{d} \approx(6.5 \pm 0.6) \times 10^{-4}$ $\mathrm{K}^{-1}$. This is very close to the linear expansion coefficients of bulk hexagonal rotator phase $\mathrm{R}_{\text {।I }}$ of alkanes, $6.5 \times 10^{-4}$ $\mathrm{K}^{-1,39}$ and of the solid surface-frozen monolayer in alkane melts, $9 \times 10^{-4} \mathrm{~K}^{-1}$. 40 The BR shown in Figure $5 \mathrm{c}$ does not change with temperature. The fact that its peak is at $q_{z}$ $=0$ indicates that the molecules are untilted, to within $\theta \leq 3^{\circ}$, from the surface normal. This structure is the same as that observed for a Langmuir film of $\mathrm{C} 1400 \mathrm{OH}$ on water at similar temperatures and at the highest coverage. Notilted phases were observed for $\mathrm{C} 14 \mathrm{OOH}$ on mercury for any other coverage $\mathrm{A}$, as was found al so for $\mathrm{C} 1400 \mathrm{H}$ on water. ${ }^{41}$ The GID peaks at coverages of 20 and $30 \AA^{2} / \mathrm{mol}$ ecule were both measured at $\mathrm{T}=27.0^{\circ} \mathrm{C}$. The peak positions, $\mathrm{q}_{\|}=1.502 \AA^{-1}$ and $\mathrm{q}_{||}=1.486 \AA^{-1}$, respectively, indicates a larger unit cell with $A=20.6$ $\AA^{2} /$ mol ecule for $30 \AA^{2} /$ mol ecule, as compared with the $A$ $=20.2 \AA^{2} /$ molecule for $20 \AA^{2} /$ molecule. The peaks' full width at half-maximum for the lower coverage is significantly larger than that of the high coverage: $\Delta \mathrm{q}_{\|}=0.036$ $\AA^{-1}$ at $A=30 \AA^{2} /$ molecule, as compared to $\Delta q_{\|}=0.016 \AA^{-1}$ at $A=20 \AA^{2} /$ molecule. This, in turn, yields a shorter crystalline coherence length of $L=0.9 \pi / \Delta q_{\mid l} \approx 160 \AA$ at the lower coverage, as compared to $L \approx 350 \AA$ for the high coverage. This reduction in coherence length may result from the coexistence of two phases on the surface at this coverage: regions of hexagonally packed, standing-up

(39) Sirota, E. B.; Singer, D. M.; King, H. E., J r.J . Chem. Phys. 1994, 100,1542

(40) Ocko, B. M.; Sirota, E. B.; Deutsch, M.; DiMasi, E.; Coburn, S.; Strzalka, J.; Zheng, S.; Tronin, A.; Gog, T.; Venkataraman, C. Phys. Rev. E 2001, 63, 032602.

(41) Fradin, C.; et al. Eur. Phys. J . B 1998, 1, 57.
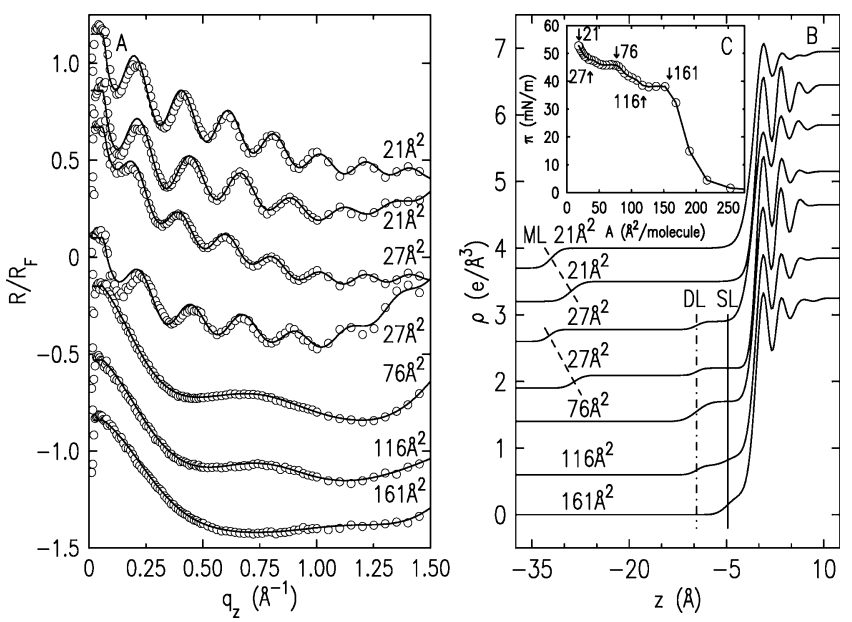

Figure 6. Same as Figure 4, but for $\mathrm{C} 240 \mathrm{OH}$. Note the formation of a single and double layer of flat-lying molecules. Thetilted and untilted standing-up phases observed at 21 and $27 \AA^{2} /$ molecule are discussed in the text.

molecules, enclosed within a double layer of lying-down molecules. At the highest coverage, all results (the hexagonal symmetry, thelinear expansi on coefficient and the coherence lengths) strongly support the conclusion that the standing-up phase is an hexatic-like LS rotator phase, similar to that of Langmuir films on water. ${ }^{3}$

For the lying-down phases no in-plane GID peaks were detected at room temperature, indicating that no longrange in-plane order exists.

B. C1800H. The results for the standing-up phases of $\mathrm{C} 180 \mathrm{OH}$ have been already published ${ }^{31}$ and will be summarized here only briefly. Similar to $\mathrm{C} 1400 \mathrm{OH}$, for thestanding-up monolayer phase of $\mathrm{C} 18 \mathrm{OOH}$, we observe an LS phase ${ }^{3}$ at the highest coverage with latticeconstants and coherence lengths similar to those of $\mathrm{C} 14 \mathrm{OOH}$. However, unlike $\mathrm{C} 14 \mathrm{OOH}$, tilted phases were found in this regime for $\mathrm{C} 180 \mathrm{OH}$. We find an Overbeck-Möbi us phase $(\mathrm{Ov})^{3}$ which has a next-nearest-neighbor tilt of the molecules in the standing-up phase, with a distorted hexagonal packing in the mercury plane and an undistorted hexagonal packing in the plane perpendicular to the molecules' long axis. As is typical for these phases, increasing the coverage causes a continuous decrease in the tilt angle and a continuous shift of the Ov phase into an untilted LS phase. For low coverages, lying-down phases, GID measurements at room temperature reveal here a one-dimensional in-plane order, quite unlike the in-plane-disordered lying-down phase of $\mathrm{C} 140 \mathrm{OH}$. These results are further discussed at the end of this section.

C. C240OH. 1. Surface-Normal Structure. The XR measurements carried out for $\mathrm{C} 24 \mathrm{OOH}$ at several different coverages are shown in Figure 6 . The fit parameters are summarized in Table 3. Thesamefitting procedures were used as for $\mathrm{C} 14 \mathrm{OOH}$.

Beginning with the 161,116 , and $76 \AA^{2} /$ moleculecurves, weobservethe formation of a full singlelayer, coexistence of a single layer and a double layer, and a $100 \%$ complete doublelayer, respectively. Thetwo scans at high coverage, 27 and $21 \AA^{2} /$ molecule, were taken for the same sample for each pair. However, the upper curve of each pair was taken $1 \mathrm{~h}$ later than the lower curve of the pair. F or 27 $\AA^{2} /$ molecul ethefits of both scans result in $60 \%$ of thearea being covered by a monolayer of standing-up molecules and $40 \%$ being covered by a double layer of lying down molecules. Despite the same relative coverage, a comparison of theXR curves reveals a clearly visible decrease in the oscillation period. As shown in Table 3, this 


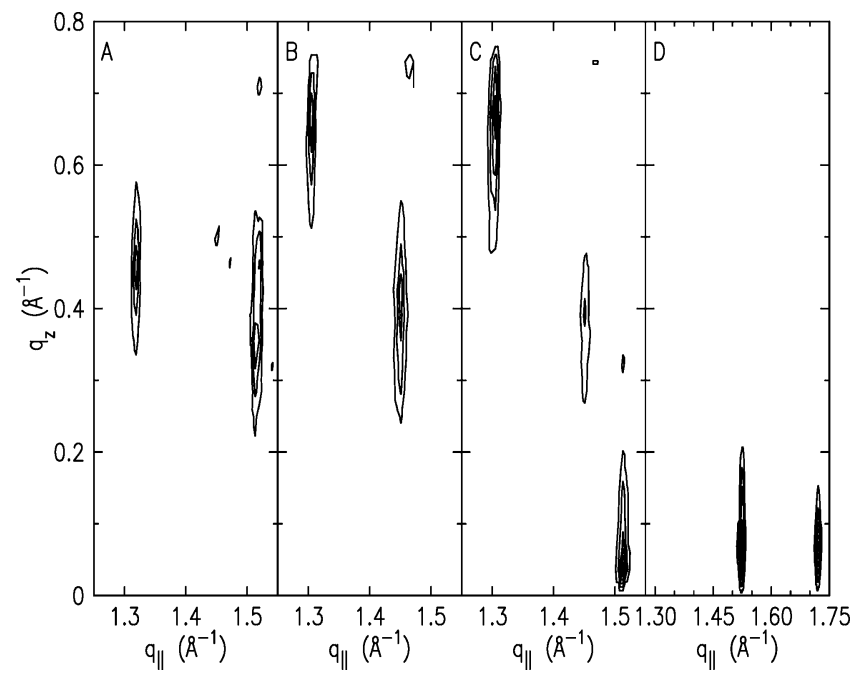

Figure 7. E qual intensity contour plots of thetime-dependent GID measurements for $\mathrm{C} 24 \mathrm{OOH}$ at a coverage of $A=27 \AA^{2} /$ molecule. The scans from (a) to (d) were taken $15,50,60$, and 90 min after film deposition.

Table 3. Nominal Coverage (A) According to the I sotherms, Layer Thickness (d), Phase, Fractional Coverage of the Topmost Layer in \% (Top), and the Roughness of the Fatty Acid-Air $\left(\sigma_{\mathrm{Fat}}\right)$ and the Mercury-Fatty Acid $\left(\sigma_{\mathrm{Hg}}\right)$ Interfaces, As Obtained from Fits to the XR Curves in Figure 6 for a C240OH Layer at $T=25^{\circ} \mathrm{C}$

\begin{tabular}{rrlccc}
\hline $\mathrm{A}, \AA^{2}$ & $\mathrm{~d}, \AA$ & phase & top, \% & $\sigma_{\text {F at }}, \AA$ & $\sigma_{\mathrm{Hg}}, \AA$ \\
\hline 161 & 4.8 & $\mathrm{SL}$ & 100 & 1.3 & 1.2 \\
116 & 9.6 & $\mathrm{DL}$ & 40 & 1.2 & 1.2 \\
76 & 9.6 & $\mathrm{DL}$ & 100 & 1.5 & 1.2 \\
27 & 28.5 & $\mathrm{ML}$ & 60 & 1.1 & 1.0 \\
27 & 32.3 & $\mathrm{ML}$ & 60 & 1.1 & 1.6 \\
21 & 28.7 & $\mathrm{ML}$ & 100 & 1.4 & 1.1 \\
21 & 32.2 & $\mathrm{ML}$ & 100 & 1.4 & 1.5
\end{tabular}

corresponds to an increasein thethickness of thestandingup part of the monolayer from $28.5 \AA$ for the first scan to $32.3 \AA$ for thelater scan. Thesecond of thesevalues equals the extended length of a $\mathrm{C} 24 \mathrm{OOH}$ molecule, I $\approx 32.2 \AA$. The same behavior occurs for the higher coverage. However, in this case both curves yield a $100 \%$ coverage by a monolayer of standing-up molecule, without a trace of a contribution from a lying-down phase. This suggests that upon increasing the coverageabovethat of a complete double layer of lying-down molecules, some of the molecules start forming a standing-up tilted phase with a tilt of $\theta \approx \arccos (28.7 / 32.2)=27^{\circ}$ from the surface normal. For rigid chains this corresponds to a shift, due to tilt, of two carbons along the chain in adjacent molecules, as expected from the requirement of space filling in closely packed chains, and as indeed found in SAMs of alkanethiols on gold substrates. ${ }^{24}$ The change with time indicates that this phase is metastable and transforms with time to an untilted monolayer phase.

2. Surface-Parallel Structure. To determine the inplane structure of the tilted and untilted standing-up monol ayer phases, we carried out GID measurements at different coverages and temperatures. To follow possible changes with time of the in-plane structure that might accompany the variations found in the XR results, we also carried out time-dependent GID scans at a few coverages. A typical time sequence is shown in Figure 7. We show here equal-intensity contour plots of the GID peaks for a coverage of $27 \AA^{2} /$ molecule. The scans were taken 15, 50,60, and 90 min after film deposition. We observe at least three different phases and often also a

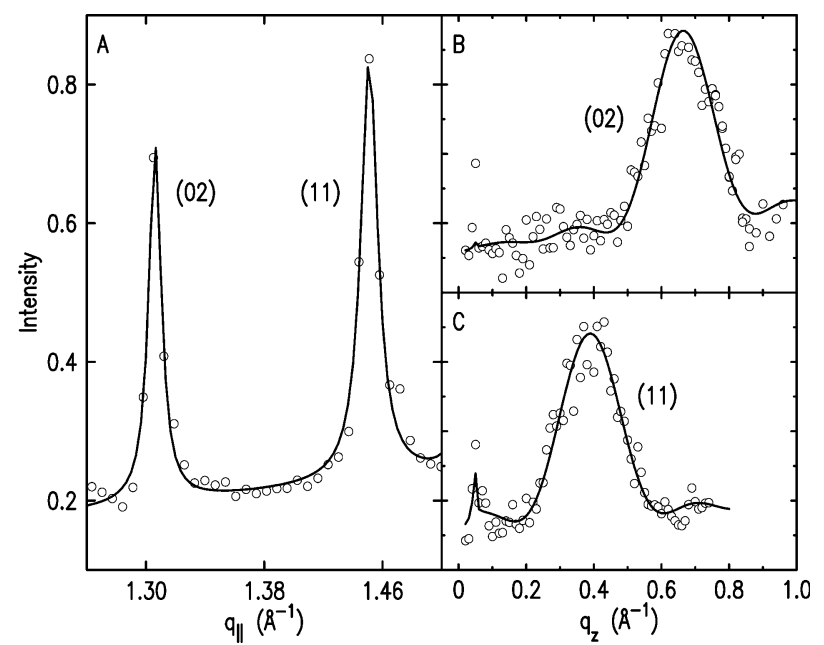

Figure 8. (a) GID scan and (b, c) BR of thecontour pl ots shown in Figure $7 \mathrm{~b}$. The fits yield a body-centered rectangular unit cell with molecules tilted by $\theta=27^{\circ}$ in a direction rotated azimuthally by $\phi=5^{\circ}$ from thenext-nearest-neighbor direction.

coexistence of some of the phases. The sequence of metastable phases termi nates after slightly over $1 \mathrm{~h}$ in a crystalline CS phase ${ }^{3}$ with a body-centered rectangular unit cell and a herringbone packing of the molecules.

Wefocus first on thetransient phases and return bel ow to discuss in detail the stable CS phase and it's temperature dependence. Figure 7a shows two peaks at $\mathrm{q}_{111}=$ $1.316 \AA^{-1}, \mathrm{q}_{\mathrm{z} 1}=0.45 \AA^{-1}$ and at $\mathrm{q}_{12}=1.512 \AA^{-1}, \mathrm{q}_{\mathrm{zz}}=0.38$ $\AA^{-1}$. These two peaks often appear together immediately after deposition of new material on the mercury surface. Attempts to associate them with a single phase results in an unphysical unit cell. Moreover, since they disappear rather quickly (a few minutes after deposition), it is not clear whether they are the only first-order peaks of this particular phase or whether other peaks may exist somewhereelsein q-space. This pattern is replaced within a few minutes by the pattern shown in Figure $7 \mathrm{~b}$. Here we find two GID peaks as well, which, contrary to those in Figure 7a, exist for up to a few tens of minutes and can be measured therefore with better reproducibility and accuracy. Their peak positions are $\mathrm{q}_{11}=1.300 \AA^{-1}, \mathrm{q}_{\mathrm{z} 1}=$ $0.66 \AA^{-1}$ and at $\mathrm{q}_{112}=1.447 \AA^{-1}, \mathrm{q}_{\mathrm{z} 2}=0.38 \AA^{-1}$. They can be assigned to the (02) and (11) diffraction peaks of a body-centered rectangular cell with dimensions $\mathrm{a}=9.66$ $\AA$ and $b=4.86 \AA$ and two molecules per unit cell. A detailed fit to the corresponding GID pattern and Bragg rods, shown in Figure 8 , yields a tilt angle $\theta=27^{\circ}$ in a direction rotated azimuthally by $\phi=5^{\circ}$ from the next nearest neighbor direction. This yields a unit cell in the plane perpendicular to the molecular long axis, with the lattice parameters $a=4.86 \AA, b=8.62 \AA$ and with a molecular area of $A=a b / 2=20.9 \AA^{2} /$ molecule. The ratio of $b / a=$ 1.77 is close to $3^{1 / 2}=1.73$, which indicates a hexagonal hexatic-like rotator phase. This phase is very similar to the Ov phase observed for stearic acid $(\mathrm{C} 1800 \mathrm{H})$ on mercury at high coverages (seeref 22 and summary above) except that for lignocericadid $(\mathrm{C} 24 \mathrm{OOH})$ the peak positions and tilt angles do not change with coverage. Another difference is the significantly sharper GID peaks, which are close to the resolution limit, $\Delta \mathrm{q}_{\text {|res }}=0.0056 \AA^{-1}$. The full width at half-maximum (fwhm) of the peaks, $\Delta \mathrm{q}_{\mathrm{l}} \approx$ $0.009 \AA^{-1}$, indicates a large crystall ine coherence length, of the order of $800 \AA$. This can be rationalized by the stronger chain-chain interaction of longer chains, which drives the system toward a closer packing and longerrange order in the crystalline layer. 


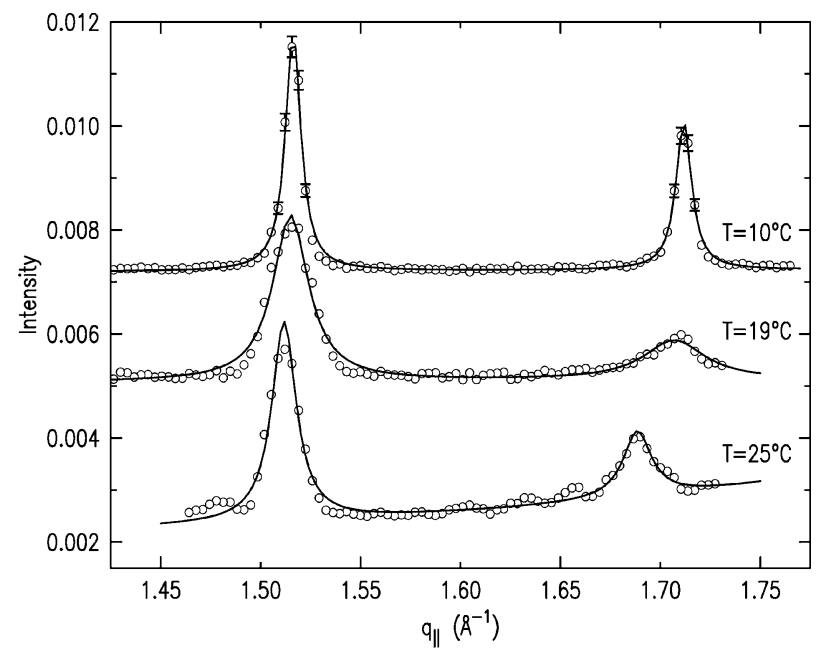

Figure 9. GID patterns for the CS crystalline phase of the standing-up monolayer of $\mathrm{C} 24 \mathrm{OOH}$ at a nominal coverage of $A=21 \AA^{2} /$ molecule, at the indicated temperatures.

The tilted Ov-like phase, discussed in the last paragraph, converts within about $1 \mathrm{~h}$ into a crystalline CS phase, the GID pattern of which is shown in Figure 7d. Similar slow relaxation, going through a complicated phase sequence, was also found for Langmuir films of tetracosanoic acid on water. ${ }^{42}$ During the conversion, a coexistence of the two phases is observed, with the GID patterns showing the peaks of both phases (Figure 7c). ${ }^{43}$ The CS phase is crystalline with a herringbone ordering. ${ }^{3}$ At room temperature, its two lowest peaks are observed at $\mathrm{q}_{\mathrm{z}}=0 \AA^{-1}$ and $\mathrm{q}_{\|}(11) \approx 1.512 \AA^{-1}$ and $\mathrm{q}_{\|}(02) \approx 1.688$ $\AA^{-1}$. This corresponds totwo untilted molecules in a bodycentered rectangular unit cell of dimensions $5.02 \times 7.44$ $\AA^{2}$. Theresultant molecular area, $18.6 \AA^{2} /$ molecule, equals the closest packing of crystalline alkyl chains of, e.g., Langmuir films on water, ${ }^{3}$ the untilted phase of the $\beta$ modification of bulk crystallinefatty acids ${ }^{45}$ and alkanes, ${ }^{45}$ and surface-frozen monolayers on alkane melts. ${ }^{44}$

The temperature dependence of the herringbone CS phase is shown in Figure 9 at 10,19 , and $25^{\circ} \mathrm{C}$. The peaks move from $\mathrm{q}_{\|}(11)=1.512 \AA^{-1}$ and $\mathrm{q}_{\|}(02)=1.688 \AA^{-1}$ at $\mathrm{T}=25^{\circ} \mathrm{C}$ to $\mathrm{q}_{\|}(11)=1.516 \AA^{-1}$ and $\mathrm{q}_{\|}(02)=1.712 \AA^{-1}$ at $\mathrm{T}=10^{\circ} \mathrm{C}$. The corresponding unit cell vectors change from $a=5.01$ to $5.02 \AA$ and from $b=7.44$ to $7.34 \AA$ upon decreasing thetemperature. Thus, thethermal expansion of this phaseis highly unisotropic. Whilethelength of the unit cell hardly changes with $\mathrm{T}$ in the a direction, in the $b$ direction the linear expansi on coefficient is $(\mathrm{db} / \mathrm{dT}) / \mathrm{b} \approx$ $9 \times 10^{-4} \mathrm{~K}^{-1}$. This is $\sim 40 \%$ higher than the isotropic expansion coefficient of $\sim 6.5 \times 10^{-4} \mathrm{~K}^{-1}$ of the $\mathrm{LS}$ phase of $\mathrm{C} 140 \mathrm{OH}$, discussed above.

The packing of the molecules in the unit cell is very dense, and the area per molecule shrinks from 18.6 to $18.4 \AA^{2} /$ molecul e over this temperature range. The peak width for the herringbone packing is always resolution

(42) Schwartz, D. K.; Schlossman, M. L.; Pershan, P. S. J . Chem. Phys. 1992, 96, 2356.

(43) On a few occasions the tilted phase peaks disappeared without the peaks of the untilted phase showing up. This may result from the formation of a disordered, or highly defective, phase. However, it may also result from a formation of an ordered phase consisting of a few largesingle-crystalline domains, rather than a two-dimensional powder comprising many small domains. In this case it is possible that peaks are not observed because none of the few existing domains happens to be oriented correctly for Bragg-diffracting the incident radiation into the detector.

(44) Ocko, B. M.; et al. Phys. Rev. E 1995, 63, 32602.

(45) Small, D. M. The Physical Chemistry of Lipids; Plenum: New York, 1986.

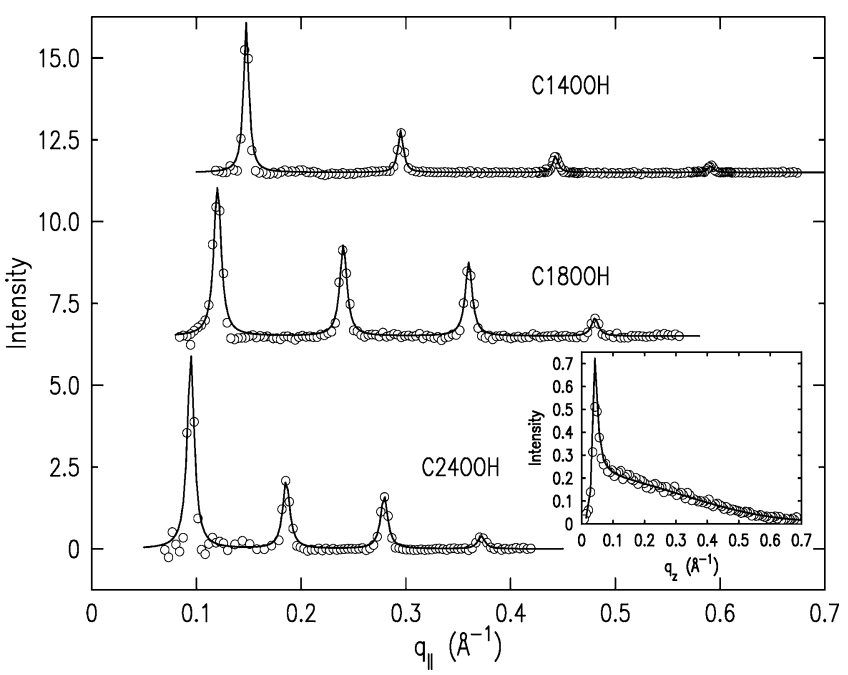

Figure 10. GID curves measured for the lying-down phases of $\mathrm{C} 1400 \mathrm{OH}$ at $\mathrm{T}=5^{\circ} \mathrm{C}$ and $\mathrm{C} 1800 \mathrm{H}$ and $\mathrm{C} 24 \mathrm{OOH}$ at $\mathrm{T}=26$ ${ }^{\circ} \mathrm{C}$; the inset shows a BR for a double layer of lying-down molecules. TheBRs of all GID peaks werefound to beidentical.

limited, indicating a crystalline coherencelength of more than $1000 \AA$, at all temperatures. It is interesting to note that upon prolonged exposuretothe beam, the peak width is observed to increase, and the peak moves to lower $\mathrm{q}_{\|}$ values. These symptoms, well-known from conventional crystallography, indicatetheproliferation of X-ray induced defects in the (two- and three-dimensional) crystalline structure.

In conclusion, for $\mathrm{C} 24 \mathrm{OOH}$, although an Ov-like phase of tilted molecules $\left(\sim 27^{\circ}\right)$ is observed on short time scales following film deposition, the final, equilibrium phase at room temperature and below is always a crystalline CS phase with a high density of $18.5 \AA^{2} /$ molecule. This is in contrast with $\mathrm{C} 180 \mathrm{OH}$, where an equilibrium Ov phase was observed, and with $\mathrm{C} 140 \mathrm{OH}$, where a hexagonal untilted rotator phase is the equilibrium phase at the highest coverages.

D. The Structure of the Lying-Down Phases. We now discuss our GID and BR measurements of the lyingdown phases of fatty acids on mercury. Figure 10 shows the GID patterns measured at low q values for the fatty acids indicated. The patterns were recorded each for a coverage corresponding to two layers of lying-down molecules. Scans for a coverage of a single layer of lyingdown molecules yield thesamepatterns, but beam damage by the intense synchrotron radiation becomes a more serious problem and prevents employing the long measuring times required for achieving good statistics. No variation is observed in the patterns upon varying the coverage within the lying-down phase. In view of the fact that in-plane GID peaks appear for $\mathrm{C} 140 \mathrm{OH}$ only below $\mathrm{T}=18^{\circ}$, the GID pattern shown was recorded at $\mathrm{T}=5$ ${ }^{\circ} \mathrm{C}$. The GID peaks of $\mathrm{C} 1800 \mathrm{H}$ and $\mathrm{C} 2400 \mathrm{H}$ were observed for all temperatures measured, $5^{\circ} \mathrm{C} \leq \mathrm{T} \leq 30$ ${ }^{\circ} \mathrm{C}$. All peaks are resolution limited, suggesting a crystalline coherence length in excess of $1000 \AA$. All scans show four diffraction peaks at positions which are multiples of the lowest-q $q_{\text {|I }}$ peak position in each curve. These are $\mathrm{q}_{\| \mid}=$ $0.1477 \AA^{-1}, \mathrm{q}_{\|}=0.1201 \AA^{-1}$, and $\mathrm{q}_{\|}=0.0932 \AA^{-1}$, corresponding to repeat distances of $\mathrm{d}=42.5 \AA, \mathrm{d}=52.3$ $\AA$, and $d=67.4 \AA$, for $\mathrm{C} 140 \mathrm{OH}, \mathrm{C} 180 \mathrm{OH}$, and $\mathrm{C} 240 \mathrm{OH}$, respectively.

The respective calculated fully extended molecular lengths are 19.6, 24.6, and $32.2 \AA$ for $\mathrm{C} 1400 \mathrm{H}, \mathrm{C} 1800 \mathrm{H}$, and $\mathrm{C} 24 \mathrm{OOH}$, rendering the repeat distances longer by 3.0-3.3 A than twice the molecular length. This, in turn, 


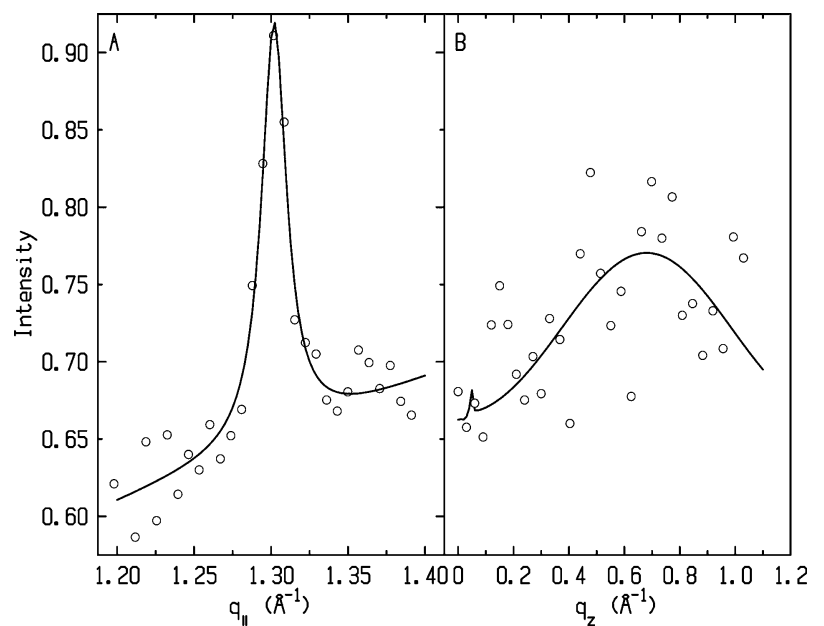

Figure 11. GID peak (a) of thelying-down doublelayer phase of $\mathrm{C} 180 \mathrm{OH}$. The BR (b) is consistent with a double layer, with the top layer's molecules residing in the hollows between the molecules of the bottom layer.

strongly suggests that the order is formed by molecular dimers rather than individual molecules. The two carboxylic headgroups reside, most likely, at the center of the dimer, and their interaction stabilizes the dimer. Since the excess $\sim 3 \AA$ length renders the distance between the carboxylic groups most probably too large for hydrogen bonding, it is likely that at least one Hg atom partici pates in the bonding at the center of the dimer. This suggestion is supported, albeit circumstantially, by the 2.8-3.0 $\AA$ diameter of the mercury atom (or ion) ${ }^{47}$ and by the $\sim 3.2$ $\AA$ interatomic distanceat the freesurface of mercury, taken from the liquid peak position in our previous reflectivity and GID measurements on bare mercury. ${ }^{19,23}$ It is also supported by the exceptionally strong GID peaks which suggest that the ordered phase comprises scatterers of high electron density.

All chain lengths studied exhibit the low- $q_{\|}$peaks indicating ordering in the direction of the molecular axis. The peaks show similar characteristics for all chain lengths: position commensuratewith twicethe molecular length, sharp peaks with resolution-limited widths, several diffraction orders, etc. By contrast, the very existence of GID peaks at $\mathrm{q}_{\|} \approx 1.3 \AA^{-1}$, which corresponds to order in the direction perpendicular to the molecular axis, is very different for different chain lengths. The q was $1.15 \leq \mathrm{q}_{\|} \leq 1.35 \AA^{-1}$. This corresponds to repeat distances $4.65 \AA \leq \mathrm{I} \leq 5.46 \AA$, which can be expected from close, or even loose, packing of molecules of widths $\sim 4.8$ $\AA$, as discussed above. For $\mathrm{C} 140 \mathrm{OH}$ no GID peaks could be observed in this range for all temperatures studied, 5 ${ }^{\circ} \mathrm{C} \leq \mathrm{T} \leq 27{ }^{\circ} \mathrm{C}$. For $\mathrm{C} 1800 \mathrm{H}$, while no GID peaks were found in this $q_{\| 1}$-range at room temperature, bel ow $\mathrm{T}=20$ ${ }^{\circ} \mathrm{C}$ a single GID peak, shown in Figure 11a, was observed at $\mathrm{q}_{\| \prime}=1.302 \AA^{-1}$. This corresponds to a repeat distance of $I=4.83 \AA$, which is typical of interchain distances of alkyl chains in several close-packed two- and threedimensional systems. The intensity of this peak is, however, rather low and the points of the corresponding $B R$, shown in Figure $11 b$ in open circles, are even more so. U nfortunately, beam damage does not allow collecting data with better statistics. Thus, the quality of the available BR is insufficient for a detailed modeling with a reasonable level of confidence. Nevertheless, the data

(46) Kraack, H.; Ocko, B. M.; Pershan, P. S.; Sloutskin, E.; Tamam, L.; Deutsch, M. Langmuir 2004, 20, 5386.

(47) Emsley, J . The Elements, 3rd ed.; Clarendon: Oxford 1998.

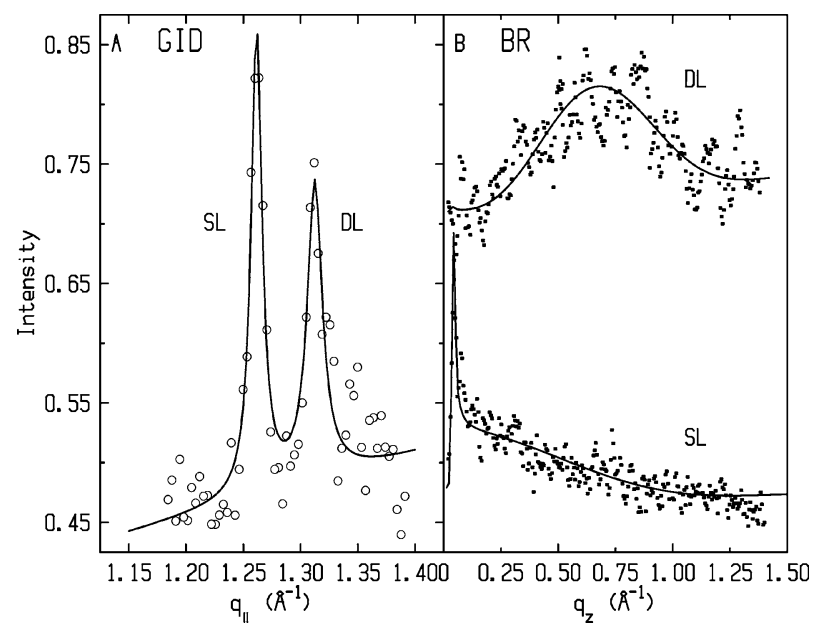

Figure 12. GID (a) and BR (b) patterns measured (points) and model-fitted (lines) for the lying-down phases of $\mathrm{C} 24 \mathrm{OOH}$ at room temperature. The GID and BR peaks correspond to a single (SL) and a double-layer (DL) of lying-down molecules.

are reasonably consistent with a model, shown by the solid line in Figure 11b, of a double layer of flat-lying cylindrical molecules, where the molecules in the second layer lie in the hollows of the molecules in the first layer. Connecting thecenters of thecross sections of twoadjacent cylinders, onein thefirst layer and the other in thesecond layer, yields a line tilted by $30^{\circ}$ from the surface normal. Thus, the BR should resemble that of a tilted molecular phase, as indeed it does, see, e.g., part b or c of Figure 8, making al lowances for the much narrower $B R$ peak there. The BR's peak here is at $q_{z} \approx 0.7 \AA^{-1}$, yielding a tilt of $\phi$ $=\arctan (0.7 / 1.302)=28^{\circ}$, which agrees well with the expected value. It is interesting to note that despite the Iow intensity of the GID peak, its width has the same resolution-limited value as that of the longitudinal GID peaks, indicating an ordering coherence length in excess of $1000 \AA$.

In contrast with the shorter chain length fatty acids, $\mathrm{C} 140 \mathrm{OH}$ and $\mathrm{C} 180 \mathrm{OH}$, for the lying-down phases of $\mathrm{C} 240 \mathrm{OH}$ at room temperature, we could readily observe two diffraction peaks, shown in Figure 12, at $\mathrm{q}_{\|}=1.262$ $\AA^{-1}$ and $1.312 \AA^{-1}$. The corresponding repeat distances are 4.98 and $4.79 \AA$ and hence belong to ordering perpendicular to the molecular axis, as discussed above. As can be seen in Figure $12 \mathrm{~b}$ for the $\mathrm{q}_{\|}=1.262 \AA^{-1}$ GID peak, the $B R$ peaks at $\mathrm{q}_{\|}=0 \AA^{-1}$ and a fit (line) yields a width corresponding to $d \approx 5 \AA$, i.e., that of a singlelyingdown layer. F or the $q_{\|}=1.312 \AA^{-1} \mathrm{GID}$ peak theBR peaks at $\mathrm{q}_{\mathrm{z}} \approx 0.66 \AA^{-1}$ and can be fitted (line) by a $\sim 27^{\circ}$-tilted layer of $10 \AA$ thickness, which corresponds to a double layer of lying-down molecules, where the molecules of the second layer reside in the hollows of the first layer. The rather large, $\sim 0.2 \AA$, shrinking of therepeat distance from the single to the double layer is a manifestation of the much stronger van der Waals intermolecular interaction within the layers, due to the existence of a second layer, which causes a tighter packing.

We now compare the molecular areas of the lying-down molecules obtained from the X-ray measurements and from fitstotheexclusion ar eas of the isotherms. Assuming a molecular width of $4.8 \AA$, obtained from the GID and also the XR measurements on thelying-down phases, the unit cell lengths obtained from the GID measurements yield mol ecular areas of 102,126 , and $162 \AA^{2} /$ mol ecule for $\mathrm{C} 140 \mathrm{OH}, \mathrm{C} 180 \mathrm{OH}$, and $\mathrm{C} 2400 \mathrm{H}$, respectively. From the relation $A_{d / 2}=(6.6 n+5) \AA^{2}$ obtained above for the exclusion area from isotherm fits assuming dimers, we 


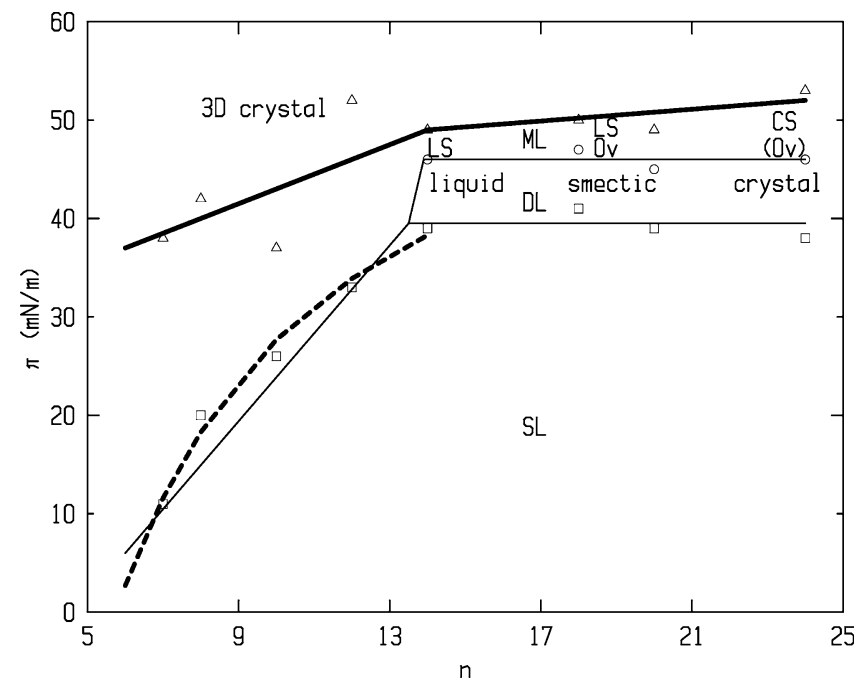

Figure 13. Surface pressure $(\pi)$-chain length (n) phase diagram for fatty acid films on mercury. For discussion, see text.

obtain 97, 124, and $163 \AA^{2} / \mathrm{molecule}$ for $\mathrm{C} 140 \mathrm{OH}$, $\mathrm{C} 180 \mathrm{OH}$, and $\mathrm{C} 240 \mathrm{OH}$, respectively. The two sets of numbers are obviously in very good agreement.

To summarize the structure of the lying-down phases, the basic buil ding block of the structure in these phases consists of extended molecular dimers, bound at their center by the two carboxylic headgroups and perhaps incorporating at least one mercury atom. At room temperature, $\mathrm{C} 14 \mathrm{OOH}$ shows no in-plane order at all. $\mathrm{C} 1800 \mathrm{H}$ shows a one-dimensional ordering along the dimer's long axis, but no order in the direction perpendicular to the dimer's long axis. This can be regarded as a one-dimensional, smectic-like order in a quasi-twodimensional layer. $\mathrm{C} 24 \mathrm{OOH}$ exhibits a two-dimensional crystalline structure, with order both along, and perpendicular to, the dimers' long axis. In C140OH a $1 \mathrm{D}$ order along the dimer's axis can be induced by lowering the temperature to $\mathrm{T}=18^{\circ} \mathrm{C}$. The $1 \mathrm{D}$ order in $\mathrm{C} 1800 \mathrm{H}$ is converted to a $2 \mathrm{D}$ order, like that of $\mathrm{C} 24 \mathrm{OOH}$ at room temperature, by lowering the temperature below $\mathrm{T}=20$ ${ }^{\circ} \mathrm{C}$. The dimers in the top layer of the double-layer phase arefound in all cases to residein thehollows of the dimers of the first layer.

E. The Phase Diagram. From the combined surface tensiometry and X-ray measurements, we can construct a preliminary phase diagram. Note, however, that although isotherms were measured for a broad range of lengths $n$, theX-ray data weremeasured only for $\mathrm{C} 14 \mathrm{OOH}$, $\mathrm{C} 180 \mathrm{OH}$, and $\mathrm{C} 240 \mathrm{OH}$.

The room-temperature projection of the three-dimensional $(A, n, \pi)$ phase diagram on the $(n, \pi)$ planeis shown in Figure 13. When looking at this plot, one must bear in mind that as $A$ is decreased from a large value of a few hundred $\AA^{2}, \pi$ increases monotonical ly, but certainly not linearly: there are A ranges where $\pi$ increases hyperbolically, where it stays constant, and wher eit increases with a large and varying slope. Film collapse, at $A \lessgtr 20 \mathrm{mN} / \mathrm{m}$, marks the transition from a quasi-2D monolayer to $3 D$ crystallites. This is marked in a bold solid linein thefigure.

For $\mathrm{C} 7 \mathrm{OOH}$ and shorter chain lengths, as themolecular area $\mathrm{A}$ is reduced the surface pressure $\pi$ starts increasing from near-zero only when the A values become very close to that of standing-up molecules, a few tens of $\mathrm{mN} / \mathrm{m}$. Thus, for $\mathrm{n} \leq 7$, nolying-down phases seem to exist, and the only phase is a monolayer of standing-up molecules. For $8 \leq \mathrm{n} \leq 12$ a singlelayer of lying down molecules, SL, followed by a monolayer of standing up molecules, ML, are most likely formed upon decreasing $\mathrm{A}$. Conclusive $X$-ray measurements in theseranges are difficult to carry out duetotherelatively small aspect ratio of the molecules, which make it difficult to distinguish standing-up from lying-down phases. Moreover, hints from corresponding films on water are not available because of the larger solubility of these short chain fatty acids in water. Also, the 3-fold higher surface roughness of water, as compared to mercury, severely restricts the measurable $q_{z}$ range and, hence, the correspond resolution.

$\mathrm{F}$ or $\mathrm{n}=14$ theX-ray and isotherm data show disordered, liquidlike SL and DL phases of Iying-down molecules followed, at higher $\pi$ values, by a standing-up LS rotator phase. $\mathrm{F}$ or $\mathrm{n}=18$ the DL phase shows a smectic-like onedimensional in-plane order of dimers. At about the same n-range the standing-up monolayer starts showing an additional hexatic phase: untilted LS and tilted OV. Somewhere between $n=18$ and $n=24$ both the lyingdown and standing-up phases become more ordered. The lying-down phases show a two-dimensional crystalline order of dimers, and the standing-up phases show a fully crystallineherringboneCS structure, although a transient Ov structure is often also observed for short periods fol lowing the deposition. In general, therefore, the order grows with increasing chain length and decreasing temperature. For example, at room temperaturetheDL phase of $\mathrm{C} 140 \mathrm{OH}$ is not ordered, $\mathrm{C} 180 \mathrm{OH}$ is smectic like and $\mathrm{C} 24 \mathrm{OOH}$ is crystalline. This trend is in line with the behavior of fatty acid Langmuir films on water, wherean increase in the chain length was found to be equivalent to a decrease in temperature. Once this effect, properly quantified, was taken into account, the $(n, \pi)$ phase diagrams of all fatty acids on water, regardless of their chain length, collapsed onto one "universal" phase diagram. ${ }^{3,13}$ Quantitative establishment of, or ruling out, a similar behavior for films of fatty acids on mercury will have to await the availability of a more complete set of data on thetemperature dependence of the phasediagram than the few measurements carried out in this study.

In general, the high-coverage standing-up phases of fatty acids on mercury are all very similar to the phases of fatty acids on water, despite the fact that they cover here a very small part of the full $(n, \pi)$ phase diagram. The high pressure at which these standing-up phases appear on mercury seems to suppress al most everywhere on the phase diagram the tilted phases observed for fatty acids on water. For $\mathrm{C} 14 \mathrm{OOH}$ we did not observe tilted phases at all. F or $\mathrm{C} 24 \mathrm{OOH}$ we observed tilted phases, but with different symmetries than those of $\mathrm{C} 24 \mathrm{OOH}$ on water. Moreover, the observed tilted phases were found to be unstable at all coverages and convert with time to the crystallineuntilted CS phase. Only $\mathrm{C} 18 \mathrm{OOH}$ exhibits here the same tilted and untilted phases found for $\mathrm{C} 18 \mathrm{OOH}$ monolayers on water. For the highest coverage the phase sequence at room temperature and bel ow seems to be the same as that of Langmuir films of fatty acids on water, but additional temperature and chain length dependent measurements are needed to quantify this assumption confidently.

The discussion above demonstrates that many details of the phase diagram can be derived from the isotherms and the (somewhat sparse) X-ray data presented here. Thus, although thegeneral features of thephasediagram, as shown in Figure 13, are well determined, the exact assignments of phase boundaries in the $(n, \pi)$ plane, and the determination of their exact temperature variation, will have to await more detailed X-ray measurements. 
The phase diagram in Figure 13 can be used to derive a rough estimate for the adsorption energies, through a comparison of the heat of vaporization with the surface pressure at the transition from the single-layer lyingdown phase to thestanding-up monolayer, marked by the bold dashed line. The details of the method are discussed in our previous publication on Langmuir films of alkanes on mercury. ${ }^{23}$ In a simplified view, the surface pressure $\pi$ should be equal tothedifference between theadsorption energy $E_{\text {ads }}$ and the heat of vaporization $\Delta H_{\text {vap. }}$. fit of the simple theoretical expression derived in ref 23 to the experimental data, shown in a dash line in Figure 13, yields adsorption energies of $5.3 \mathrm{~kJ} /\left(\mathrm{CH}_{2} \mathrm{~mol}\right)$ for a methyl group and $\mathrm{E}_{\text {ads }} \approx 28 \mathrm{~kJ} /(\mathrm{CHOOH} \mathrm{mol})$ for the carboxylic headgroup. Theresult for a methyl group agrees very well with the $5.4 \mathrm{~kJ} /\left(\mathrm{CH}_{2} \mathrm{~mol}\right)$ obtained from alkanes on mercury. ${ }^{23}$ The adsorption energy of the carboxylic headgroup is five times larger, making the headgroup adsorption energy comparable to that of the full alkyl chain in short molecules. Vertical orientation of the molecule relative to the surface maximizes the headgroup-subphase contact, while surface-parallel orientation maximizes the alkyl-subphase contact. Thus, the relative magnitude of these two interactions will determine the molecular orientation at the surface at low surface pressures. When theformer is larger, at short chain length, the molecules stand up spontaneously at low pressures. When the later is larger, at longer chains, the molecules tend to lie down and can be induced to stand up only by increasing the pressure. This explains our observation of only a standing-up phase at $\mathrm{n} \leq 7$ and a sequence of a lying down phaseat low $\pi$ followed by a standing up phase at higher $\pi$ at higher $n$. Thelargeadsorption energy of the headgroup al so explains why short-chain fatty acids form Langmuir films on mercury, while the samelength alkanes do not form Langmuir films on mercury, and rather prefer to form 3D crystallites. ${ }^{23}$ The transition among the various phases found, and the very existence of a the lying-down phases, can be rationalized, in principle, within a balance among several competing interactions. A major factor is the Hamaker constant of theliquid metal-organicfilm-vapor system which islarge and positive in contrast with the small and negative Hamaker constant found for Langmuir films on water. This favors herea thin layer of lying-down molecules over a thick layer of standing-up molecules (albeit consisting of islands), as found on water. Other factors are the bulk cohesiveenergy, which favors standing-up mol ecules with maximal chain contact, as in bulk, the interaction of the acidic headgroup with the mercury (attractive) and the chains (repulsive) and the attractive chain-mercury interaction. Work on these issues is in progress.

\section{F. Conclusion}

The major features of the phase behavior of fatty acid films on mercury were determined in the present study. Unlike fatty acid molecules on water, which show only standing-up phases, ${ }^{3}$ on one hand, and alkanes on mercury, ${ }^{23}$ which show only lying-down phases, on the other hand, we observed here both lying-down and standing-up phases. These differences demonstrate the importance of the subphase as well as the headgroup in determining the structure of the Langmuir film.

The lying down phases differ from those of alkanes on mercury by showing disorder, 1D-smectic-like order, and 2D-order of molecular dimers, depending on chain length, while for alkanes no in-plane order was found for any chain length. The standing-up phases are found here to besimilar tothose of fatty acids on water, with increasingly higher ordering with chain length. However, due to the much higher pressures required togeneratethese phases, untilted stable phases aremostly observed, al beit transient tilted phases do appear for a short time following film deposition.

Finally, thepresent results, in conjunction with similar studies of Langmuir films of alkanes ${ }^{23}$ and al cohols ${ }^{46}$ on mercury should provide for a deeper understanding of the relative importance and role of thesubphase-headgroup and subphase-alkyl chain interactions in determining thestructure of, and molecular orientations in, thesefilms. Clearly, thestanding-up phases appear only when a strong headgroup-subphase interaction exists. For alkanes, lacking such headgroups, only lying-down phases are found. ${ }^{23}$ However, more subtle differences in structure and phase sequence also depend on the relative strength and nature of these two interactions. These issues will be addressed in future publications.

Acknowledgment. Support to M.D. by the U.S.I srael Binational Science Foundation, J erusalem, and to P.S.P. by theNSF (Grant N o. DM R-0124936) is gratefully acknowledged. Wethank D. Vaknin (Ames) for generous advice and drawings of the trough. BNL is supported by U.S. DOE, Contract No. DE-AC02-98CH10886.

\section{LA049977Y}

